\title{
EL CONSEJO NACIONAL DE LA ECONOMÍA Y DEL TRABAJO DE ITALIA
}

(Una reflexión sobre la Ley de Reforma)

\author{
MASSIMO SICLARI \\ Docente de la Universidad Gabrielle \\ D'Anunzio. Teramo (Italia) \\ Letrado de la Corte Costituzionale
}





\title{
EL CONSEJO NACIONAL DE LA ECONOMIA Y DEL TRABAJO DE ITALIA *
}

(Una reflexión sobre la Ley de Reforma)

\author{
POR \\ MASSIMO SICLARI \\ Docente de la Universidad Gabrielle D'Anunzio. \\ Teramo (Italia) \\ Letrado de la Corte Costituzionale
}

En la Gaceta Oficial núm. 3, de 5 de enero de 1987, ha sido publicada la Ley núm. 936, de 30 de diciembre de 1986 que, si bien se intitula, genéricamente, Normas sobre el Consejo de la Economía y del Trabajo, constituye una auténtica reforma de la regulación vigente de dicho Consejo. Efectivamente, el artículo 26 de la citada Ley deroga expresamente la Ley núm. 33, de 5 de enero de 1957, vigente hasta ahora en la materia.

1. De reforma del CNEL ya se hablaba tiempo atrás. Desde su aparición, se consideró que la disciplina del Consejo restringía excesivamente las funciones que la Constitución había pretendido confiarle y algunos comentaristas creían ( $y$ creen aún) que el reajuste de la posición del CNEL en el marco del sistema constitucional debía ser reconducido a la misma Ley institutiva (véase, en este sentido, G. MOTZO y otros, «Linee per una riforma del CNEL», en La Costituzione economica, dir. por M. D'Antonio, Milano 1985, págs. 357 y ss.; también, el Informe de la Comisión parlamentaria para las reformas institucionales presentada a las Presidencias de las Cámaras el 29 de enero de 1985, págs. 73 y ss.).

A esta posición se le opuso otra tendente a la supresión del CNEL (y explicitada -además de en las sesiones de la Comisión parlamentaria para las reformas institucionales - en el Proyecto de Ley Constitucional núm. 1511, presentado el 2 de noviembre de 1985 en la presidencia del

* Traducido por Remedio SÁnchez FerRiz. 
Senado por iniciativa del senador Pasquino, entre otros, relativo a la Abrogación del artículo 99 de la Constitución y supresión del Consejo Nacional de la Economia y del Trabajo) partiendo de la base de que tal órgano no encuentra justificación alguna en la lógica de nuestro sistema constitucional. Lógicamente, aquí se polarizan dos valoraciones entre las que existe toda una serie de posiciones intermedias sobre las que no podemos detenernos ahora; un análisis completo del debate doctrinal en torno al CNEL excede, desde luego, los límites de este trabajo cuyo propósito no es otro que poner de relieve las más relevantes innovaciones aportadas por la Ley núm. 936 de 1986 con el fin de divisar qué posibilidades ofrece la reforma para un relanzamiento (rectius: para un lanzamiento) del papel del CNEL en nuestro sistema.

Somos conscientes de que para valorar cuál pueda ser en el futuro el «rendimiento" de la institución CNEL no es suficiente el simple análisis de una (siquiera) importante modificación legislativa y de que sería más oportuna una consideración de la efectiva mutación de las relaciones en el ámbito del sistema de los poderes públicos. Ello podrá ser objeto de estudio dentro de algún año a la vista de la experiencia ofrecida por la aplicación de la nueva Ley. No parece, pues, inútil emprender este análisis y menos si consideramos que, entre la tentación de liquidar al CNEL como a «una vieja barraca corporativa, útil, únicamente para asegurar ingresos a sindicalistas jubilados» (A. NEGRI, «Variazioni sul tema CNEL», en Critica del Diritto, 1976, núm. 9, pág. 14) siguiendo lo más maudit de los intelectuales italianos, y la indicación de una de las voces más autorizadas de la doctrina iuspublicista, según la cual «la dificultad de restituir al Consejo Nacional el papel que le corresponde no es otra cosa que el síntoma de la crisis profundisima en que se halla inmerso todo el Estado italiano" (L. PALADIN, «Ostacoli e propettive nei rapporti fra regioni e CNEL», en Le Regioni, 1978, pág. 56) parece preferible seguir esta última posición para darse cuenta de si la "vieja barraca» está realmente para quemar o sirve aún, y en qué medida, cuanto menos como indicador del estado de nuestras instituciones.

2. Ya hemos dicho que las instancias de reforma del CNEL se hicieron sentir apenas promulgada la Ley constitutiva. Pero - salvo algunas posiciones marginales - un proceso de reforma propiamente dicho, del que derivaría la disciplina actual, sólo tomó forma en 1976 coincidiendo con el inicio del quinto mandato del Consejo, momento en que el entonces Presidente del Consejo de Ministros decidió encomendar al mismo CNEL la labor de preparar un esquema de reforma. Para la aprobación del Proyecto han sido necesarios varios años, durante los cuales, además de haberse celebrado diversos debates en la sede del Consejo (del que formaban parte prestigiosas personalidades del mundo del trabajo y de la Universidad: basta pensar en G. Giugni, B. Storti, P. Sette, A. Ardigo), han sido consultados algunos ilustres estudiosos (G. Chiarelli, F. Barbano, S. D'Albergo, A. Predieri, S. Galeotti, G. Zangari). 
El último momento de este proceso de estudio y preparación lo ha constituido un Proyecto, aprobado por unanimidad por la asamblea los dias 20, 21 y 22 de octubre de 1982 (la documentación más representativa de la elaboración del Proyecto de Reforma se halla en el volumen -coordinado por el mismo CNEL - titulado La riforma del CNEL. Studi e documenti, Roma 1983, pero deben también consultarse los apuntes críticos hechos por G. GIUGNI en el artículo «La riforma del Consiglio nazionale dell'economia e del lavoro", en Foro Italiano, 1985, V, 48 y s.), posteriormente transformado, en buena parte, en el Proyecto de Ley presentado por el Presidente del Gobierno Spadolini, el 9 de junio de 1982, al Senado. El final (anticipado) de la VIII Legislatura provocaría el decaimiento del Proyecto, presentado de nuevo, sin embargo, aunque con modificaciones sustanciales, al Senado el 24 de noviembre de 1983 (para una comparación entre este Proyecto y su precedente, cfr. G.MOTZO y otros, op. cit., págs. 358 y ss.).

Así se inició el iter de aprobación del Proyecto que termina tres años después con la promulgación de la Ley que vamos a examinar. Cabe aquí poner de relieve que el coetáneo desarrollo de los trabajos de la Comisión parlamentaria para las reformas institucionales, presidida por el honorable Bozzi, pudo haber aconsejado que se esperara a conocer su resultado; en cambio, y pese a que en dicha Comision los representantes de la Izquierda Independiente hicieran una propuesta de upura y simple abolición del CNEL", la Comisión "se ha guiado prevalentemente por la idea de mantener el texto actual del artículo 99 (de la Const.)", habida cuenta, precisamente, del «avanzado estado del examen en el Senado» del Proyecto de Ley de Reforma (cfr. «Informe de la Comisión Parlamentaria para las Reformas Institucionales» presentado a la Presidencia de la Cámara el 29 de enero de 1985, págs. 73 y s.).

3. Pero centrémonos ya en las innovaciones introducidas por la Ley núm. 936 de 1986 en la disciplina del CNEL con la advertencia de que sólo vamos a ocuparnos de las más relevantes, o sea, de las relativas a la composición del Consejo (art. 2) y a los procedimientos de designación (arts. 3-5), a la remoción de la prohibición del mandato imperativo (art. 7 , pfo. 2), a su función de observatorio del mercado de trabajo (art. 10, c), al ejercicio de sus funciones de iniciativa legislativa y de participación en la elaboración de la legislación (art. 10, $i, f, g$ ), a la nueva configuración del poder reglamentario (art. 20) y a la inédita competencia relativa al registro de los convenios colectivos (art. 17).

4. El artículo 2 de la Ley de Reforma establece la nueva composición del Consejo que es ahora de ciento once expertos y representantes de los sectores de la producción, además del Presidente. Así, pues, el número total de sus miembros aumenta considerablemente respecto del anterior que era de ochenta, contando con el Presidente. 
Doce de los ciento once componentes, los "expertos" a que se refiere el artículo 99.1 de la Constitución deben ser "cualificados exponentes de la cultura económica, social y jurídica, de los cuales:

a) ocho son nombrados por el Presidente de la República;

b) cuatro son propuestos por el Presidente del Gobierno».

Asi reza el artículo 2.1 que, en parte, ratifica el artículo $2, g$ de la Ley de 1957 (por lo que se refiere a los nombramientos "presidenciales") y en parte se separa de él (antes, en efecto, los «expertos» eran veinte en total: los de designación no presidencial debian ser designados por diversos entes e instituciones como el CNR, algunos consejos superiores de Ministerios, el CICR, etc.). Precisamente sobre la designación de los expertos ha surgido un primer problema en la aplicación de la Ley que examinamos. Efectivamente, el Presidente Cossiga no ha procedido a designar los ocho miembros del CNEL (y aún hoy, diciembre de 1987, no lo ha hecho) por negarse a hacerlo sin previa propuesta del Gobierno aun cuando la Ley parece prever lo contrario (cfr., al efecto, también, el art. 3). Más aún, según declaración periodística hecha por el entonces Subsecretario de la Presidencia del Gobierno, Giuliano Amato, en el momento de proceder a la promulgación de la Ley el «Presidente Cossiga hasta se habría planteado si no procedía negarse a firmar la Ley y remitirla de nuevo a las Cámaras por cuanto aquélla le atribuia poderes de designación en un campo no previsto por la Constitución».

La Ley no fue reenviada a las Cámaras, explicaba Amato, porque el Jefe de Estado "se había convencido de que podía ser interpretada en el sentido de que los ocho miembros del CNEL nombrados por él deberian, en todo caso, ser designados por el Gobierno" (cfr. G. C. F., «Cossiga non fa le nomine CNEL", en La Stampa, de 18 de febrero de 1987; véase, también, sobre este punto, P. CALANDRA, "La prassi di Cossiga», en Quaderni Costituzionali, 1986, pág. 552). El caso encuadra coherentemente en la interpretación rigurosa de los poderes propios que el actual Jefe de Estado ha hecho suya desde el inicio de su mandato. Cierto que en el caso que nos ocupa se trataba de un poder de importancia secundaria aunque por ello mismo merece reflexión. En un momento como el actual en el que la batalla política se libra sin desechar cualquier medio - hasta el punto de provocar ataques insensatos a la Presidencia a raíz de la disolución anticipada de las Cámaras decidido a finales de abril de este año, tras una crisis de Gobierno que no permitía encontrar otra salida (pese a las contrarias declaraciones oficiales)—, en un momento como el actual, decíamos, parece legítimo que el Presidente asuma una interpretación rigurosa de sus poderes propios, única arma que le queda para contrarrestar las actuales tendencias desestabilizadoras. 
Volviendo a la regulación de la composición del Consejo, cabe destacar que se ha llevado a cabo una profunda modificación del número de los arepresentantes de las categorías productivas de bienes y servicios en los sectores público y privado" que de cincuenta y nueve han pasado a ser noventa y nueve. Una simple comparación con la Ley de 1957 permite observar que se ha aumentado la representación de casi todas las categorías. Sin embargo, la Ley de Reforma es menos precisa que la anterior en punto a la determinación del número de los representantes de cada uno de los sectores productivos con derecho a estar representados en el CNEL. Evidentemente, el legislador ha pretendido remitir a la fase de aplicación una más detallada determinación de las diversas representaciones.

Por lo que respecta a los nombramientos, el artículo 4, último párrafo, establece la forma de decreto del Presidente de la República emitida a instancia del Presidente del Gobierno, previa deliberación en Consejo de Ministros. Particularmente complejo es el iter establecido - en los primeros siete párrafos del artículo 4- para llegar a la referida deliberación y que creemos conveniente reproducir aquí:

«1. Nueve meses antes del final del mandato de los miembros del Consejo, la Presidencia del Consejo dará aviso de dicho final y de los plazos a que se refiere el presente artículo, publicándose en la Gaceta Oficial.

2. Las organizaciones sindicales nacionales, dentro de los treinta días siguientes a tal publicación, remitirán a la Presidencia del Consejo de Ministros las designaciones de los representantes de las categorias productivas a que se refiere el artículo 2 .

3. El Presidente del Gobierno, en los treinta días siguientes y oídos los ministros competentes, determina la relación de representantes de las organizaciones sindicales más representativas y lo comunica a todas las organizaciones con derecho de designación.

4. El recurso contra tal acto se presenta, por las organizaciones, en el plazo de treinta días desde su comunicación, ante la Presidencia del Consejo de Ministros que procede a comunicarlo a las otras organizaciones interesadas.

5. En el recurso las organizaciones deberán aportar todos los datos necesarios para poder determinar el grado de representatividad, especialmente lo relativo a la amplitud y difusión de sus estructuras organizativas, en la consistencia numérica, a su efectiva participación en la formación y estipulación de los convenios colectivos o pactos de carácter 
nacional y a la composición de las controversias individuales y colectivas de carácter laboral.

6. La misma documentación puede presentar en defensa de sus propios intereses, y dentro de los treinta días siguientes a la notificación del recurso, las organizaciones contrainteresadas.

7. El recurso debe resolverse, con audiencia de las partes y en el plazo de cuarenta y cinco días, por resolución de la Presidencia del Gobierno previa deliberación en Consejo de Ministros".

La regulación apenas transcrita tiende a evitar, en lo posible, que se perpetúen aquellas situaciones de impasse -incluso de años- que han caracterizado cada renovación del CNEL y que en buena medida han contribuido a la crisis del Instituto. Otro tanto cabe decir de la regulación ad hoc de los recursos que supone un intento de poner fin -0 al menos de reconducir a ciertos esquemas- el importante contencioso que, especialmente en los últimos años, se ha planteado con los nombramientos de los miembros del CNEL (al respecto existe ya una jurisprudencia administrativa consistente: cfr. Consiglio di Stato, sec. IV, 3 de diciembre de .1986, núm. 824, en Foro Italiano, 1987, III, 229 y ss., con una nota de R. Ferrara a la que nos remitimos para más referencias jurisprudenciales).

Particular atención merece también el quinto párrafo de los transcritós por cuanto -caso quizás único en la legislación italiana- establece algunos criterios de valoración del grado de representatividad de las organizaciones sindicales (amplitud y difusión de sus estructuras organizativas, consistencia numérica, participación efectiva en la formación y estipulación de los contratos y pactos colectivos nacionales asi como en la resolución de las controversias laborales individuales y colectivas). Parecería que nos encontramos ante un cambio radical de la actitud del Parlamento por lo que se refiere a las organizaciones sindicales: ya no encontramos la apodictica (y ya casi ritual) mención de las «organizaciones sindicales más representativas» sino la enunciación del parámetro para la valoración, en términos de concreción, de tal representatividad. La futura elaboración legislativa nos dará la medida de la efectividad (o de la accidentalidad) de este cambio que en todo caso es un (no el único) síntoma de la grave crisis en que parecen hallarse los sindicatos tradicionalmente considerados como «más representativos».

La Ley núm. 936 de 1986 nada innova sobre las modalidades de selección y nombramiento del Presidente del CNEL que continúa siendo elegido aparte de los componentes del Consejo y nombrado por Decreto del Presidente de la República a propuesta del Presidente del Gobierno, previa deliberación del Consejo de Ministros (art. 5). El cargo tiene una 
duración de cinco años, pudiendo ser confirmado (regla que se extiende a todos los miembros del Consejo según el art. 6).

Permítasenos avanzar alguna conclusión sobre las normas relativas a la composición y a las modalidades de nombramiento de los miembros del CNEL. No cabe duda sobre la valoración positiva que merece el esfuerzo realizado por el legislador en orden a racionalizar los procedimientos de designación, pero no son menos relevantes, en mi opinión, las disposiciones referidas al número de los miembros: mientras que antes se establecía una relación de veinte "expertos" frente a cincuenta y nueve «representantes de las ramas de producción», ahora tal proporción es de doce a noventa y nueve. Parece, por tanto, que se ha reforzado notablemente el carácter del CNEL como órgano de representación de intereses. Lo que, de otra parte, puede verse confirmado por una disposición relativa al status de sus miembros: se trata del artículo 7, párrafo 2 en cuya virtud, "los miembros del CNEL pueden ser revocados a instancia de las instituciones, entes $u$ organizaciones que los han designado..." La regulación anterior, en cambio, imponia la prohibición del mandato imperativo contribuyendo asi a configurar un Consejo de naturaleza bastante ambigua puesto que tal prohibición es propia de los órganos de representación política en los que todos sus miembros son portadores - al menos en teoría- de intereses generales (cfr. B. CARAVITA, «Prime riflessioni sul ruolo del CNEL», en Ires materiali, 1984, núm. 3, pág. 53).

Pero antes de emitir un juicio definitivo sobre las innovaciones con que la Ley núm. 936 de 1986 contribuye a una configuración más precisa del Instituto, vale la pena que nos detengamos en la regulación de las competencias del CNEL que en ella se contiene.

5. Empecemos por la consideración de la que puede ser calificada como la más importante de las funciones confiadas al CNEL por la Constitución: la iniciativa legislativa.

El artículo 10 de la Ley de Reforma, al enumerar las atribuciones del CNEL, dice en su letra i) que "tiene iniciativa legislativa". Puesto que nada más dice la Ley al respecto y puesto que no cabe duda alguna sobre la derogación de la Ley anterior, núm. 33 de 1957, puede afirmarse que la iniciativa legislativa del CNEL puede hoy desplegarse con mayor amplitud que antes. Efectivamente, el artículo 10 de la Ley de 1957 contenía algunas limitaciones: de una parte, establecia que no podía ejercerse la iniciativa del Consejo para las leyes constitucionales ni para las leyes tributarias, presupuestarias, de delegación o de autorización para la ratificación de tratados internacionales; de otra, establecía también que, en todo caso, las propuestas de ley elaboradas por el CNEL debían ser remitidas por su Presidente al del Consejo de Ministros que, en el plazo de tres días, debia remitirlas a su vez a una de las dos Cámaras. Un tercer tipo de limitaciones se contenía, además, en el artículo 11 de la Ley del 57 consistente en una 
verdadera prohibición de la iniciativa del CNEL en las materias sobre las cuales el Gobierno o una de las Cámaras hubieran solicitado un dictamen o sobre las cuales hubiera sido presentado un Proyecto de Ley.

La reforma que examinamos, pues, sale al paso de las críticas que, desde diversos sectores se habian dirigido a las mencionadas limitaciones (cfr., entre otros, E. SPAGNA MUSSO, L'iniziativa nella formazione delle leggi italiane, I, Milano 1958, pág. 88; G. CHIARELLI, “Consiglio nazionale dell'economia e del lavoro», en Enciclopedia del Diritto, IX, Milano 1961, págs. 248 y ss.; F. CUOCOLO, Saggio sull'iniziativa legis/ativa, Milano 1971, págs. 73 y ss.; A. PIZZORUSSO, «Delle fonti del Diritto. Art. 1-9», en Commentario del Codice Civile, dir. por A. Scialoja, y G.BRANCA Disposizioni sulla legge in generale, Bologna-Roma 1977, págs. 188 y ss. Véase también la opinión discrepante manifestada al respecto por C. MORTATI, Istituzioni di Diritto Pubblico, vol. II, Padova 1976, págs. 731 y s., donde se duda de que las citadas limitaciones supongan lesión alguna para la libertad de iniciativa del Consejo).

Por descontado que, pese a la derogación de la regulación anterior, sobre la iniciativa legislativa del CNEL siguen operando las limitaciones derivadas del sistema constitucional, aun cuando se repitiera su mención en la enumeración del citado artículo 10 de la Ley de 1957: nos referimos a los Proyectos de Ley de presupuestos a los de autorización para ratificar tratados internacionales que, como se sabe, quedan por expreso mandato constitucional, «reservados» a la iniciativa del Gobierno (como también los Proyectos de Ley de conversión de los decretos-leyes). En cambio, no parece haber obstáculos por lo que respecta a la presentación de proposiciones de leyes constitucionales, de leyes de delegación y de leyes tributarias: en efecto, la Constitución prevé para las mismas limitaciones que afectan, respectivamente, a la fase de aprobación e integración de su eficacia (procedimiento del art. 138) o sólo a la fase de aprobación (reserva de Ley de pleno, según el art. 72 , pfo. 4) o, por último, a la posibilidad de someterse al referéndum abrogativo (art. 75, pfo. 2). Ninguna limitación se impone, sin embargo, en punto a la iniciativa de tales leyes.

Conviene, no obstante, subrayar que la abolición de los referidos límites de la iniciativa legislativa del Consejo no comportan necesariamente el que ésta vaya a adquirir una mayor relevancia. Ciertamente, parte de la doctrina considera «modestísimos» los resultados obtenidos hasta ahora por el Consejo en este campo; tanto es asi que se ha llegado a proponer la supresión de dicho poder de iniciativa (asi, por ejemplo G. MOTZO y otros, op. cit., pág. 363). En todo caso, creemos que habria de tenerse en cuenta el escaso relieve que en conjunto ha tenido la iniciativa legislativa no parlamentaria ni gubernamental en los cuarenta años de experiencia constitucional republicana (sobre este punto, véase M. PATRONO, «Procedimento legislativo", en Novissimo Digesto Italiano. Appendice, vol. V, Torino 1984, pág. 1351) aunque - como se ha destacado, también recientemente «no cabe establecer una preeminencia formal entre los diversos 
tipos de iniciativa» (así, A. A. CERVATI, “Commento all'art. 71», en A. A. CERVATI y G. GROTTANELLI DE SANTI, La formazione delle leggi, t. I, 1, en Commentario della Costituzione, dir. por G. Branca, Bologna-Roma 1985, pág. 64). Por último, no parece indiferente el hecho de que la Ley núm. 936 de 1986 haya colocado el poder de iniciativa en el último lugar entre las competencias del CNEL enumeradas por el artículo 10; ello es síntoma, a nuestro juicio, de que el legislador ha considerado esta competencia casi residual respecto de las otras.

La supresión, pues, de los límites contenidos en los artículos 10 y 11 de la Ley de 1957 no debe ser excesivamente enfatizada aunque no puede negarse en principio que de ella deriva una revitalización del poder de iniciativa del CNEL.

De otra parte, parece que la función esencial del CNEL sigue siendo la de carácter consultivo (cfr., por todos, G. CHIARELLI, op. cit., págs. 256 y ss.), lo que justificaría la mayor atención que la ley concede a ésta aunque tampoco cabe afirmar que se haya operado un reforzamiento de la misma. Por ejemplo, no se ha establecido el carácter preceptivo de los informes del CNEL (pese a haber sido invocado desde diversas partes) a menos que se quiera considerar como prescripción de un informe obligatorio la previsión contenida en la letra b) del artículo 10, según la cual, el Consejo «examina, en sesión al efecto, el documento programático que el ministro de Economía y el del Tesoro deben presentar al Parlamento en cumplimiento de lo dispuesto en el artículo 15 de la Ley núm. 468, de 5 de agosto de 1978". La ley se limita a prescribir un "examen» pero de ello no se desprende - cuanto menos explícitamente - una obligación para el Consejo de emitir su parecer sobre tal documento (aunque el Consejo siempre podría - pero por propia decisión- hacer llegar al Gobierno las observaciones que estimase oportunas). En definitiva, parece que, tampoco por esta vía, la ley vaya a reforzar la presencia del CNEL en los círculos de decisión.

En cuanto a la función de colaborar en la elaboración de la legislación económica y social de acuerdo con lo establecido en el artículo 99, último párrafo, de la Constitución (actividad afín pero - dada su específica finalidad, constitucionalmente prescrita - diversa de la consultiva), el artículo 10, letras $f$ ) y $g$ ) dispone que la misma puede ejercerse por el Consejo del siguiente modo: o expresando su parecer y realizando estudios e investigaciones a petición de las Cámaras, del Gobierno, de las Regiones y de las Provincias autónomas, o bien formulando observaciones y propuestas a iniciativa propia. El artículo 12 determina que tales observaciones y propuestas deben ser remitidas al Gobierno así como a las Cámaras, a las Regiones y a las Provincias autónomas que, en el ámbito de sus respectivos ordenamientos, disciplinan las modalidades de utilización de aquéllas. Tal colaboración puede, por otra parte, referirse también a la actividad de las Comunidades Europeas y de organismos internacionales de los que Italia forme parte. 
Se trata de una notable ampliación del espectro de posibilidades de intervención del Consejo en los procedimientos de formación de los actos normativos (bastaria en este punto consultar la correspondiente, y bien magra, disposición de la normativa precedente, el art. 8, pfo. 4, de la ley del 57). Pero también en este caso debe evitarse una sobrevaloración de las intervenciones con que podrá participar el CNEL en la legislación económico-social. Es impensable, en efecto, que los entes y las organizaciones representadas en el Consejo vayan a dejar, a partir de ahora, de defender sus intereses directamente ante los centros de decisión para someterse a los riesgos de dilaciones temporales o de mediaciones preliminares que la discusión en el ámbito del CNEL comporta inevitablemente. La experiencia cotidiana demuestra todo lo contrario (cfr., las Actas del Congreso celebrado sobre este tema, Potere, poteri emergenti e loro vicissitudini nell'esperienza giuridica italiana, coordinado por G. Piva, Padova 1986, y alli, particularmente, las Comunicaciones de M. S. GIANNINI -págs. 33 y ss.-, P. TUPIA -págs. 145 y ss. - y G. GUARINO —págs. 377 y ss.—, así como las comunicaciones de T. MUZI FALCONI - págs. 193 y ss.- y M. PELLEGATTA -págs. 203 y ss.), y no parece previsible que vaya a producirse un cambio significativo a menos que se pretenda disciplinar la actividad de lobbying configurando al CNEL como canal privilegiado para representar los intereses que sus miembros representan. Pero, aun suponiendo que esto fuera asi, no parece que sea garantía de que los grupos de intereses dejen de utilizar los otros -y más directos- canales de influencia sobre la legislación.

Otra innovación merecedora de consideración es la que se ha producido con relación a la potestad reglamentaria del CNEL:

El artículo 17 de la ley núm. 33 del 57 contenia solamente una facultad de "redacción" de normas reglamentarias por parte del Consejo. Sobre los reglamentos internos, en efecto, se disponía que el Decreto del Presidente de la República que había de darles cobertura sólo se expedía a propuesta del Presidente del Gobierno. Esta normativa planteaba algunas dudas: efectivamente, se puso de relieve que «los reglamentos internos, como tales, son expresión de la potestad de autogobierno propia de toda institución, entendiéndose incluidos los órganos colegiados» (G. CHIARELLI, op. cit., pág. 250). De otra parte, se sostenía que la propuesta del Presidente del Gobierno debia asumir con carácter vinculante el acuerdo del CNEL (véase, en este sentido, P. F. GROSSI, «Breví note sul regolamento del Consiglio nazionale dell'economia e del lavoro", en Giurisprudenza Costituzionale, 1958, pág. 935 y C. MORTATI, op. cit., vol. I, pág. 588) aunque esta última interpretación no ha sido secundada en la práctica (véase, al respecto, las situaciones creadas en torno a la aprobación del primer reglamento, en P. F. GROSSI, op. cit., págs. 834 y ss.).

Estas discusiones doctrinales ya no tienen hoy razón de ser puesto que el artículo 20 de la ley núm. 936 establece la potestad reglamentaria autónoma del CNEL, en cuanto a las modalidades de ejercicio de sus pro- 
pias competencias (a excepción de las relativas a las asignaciones, dietas de asistencia y reintegro de gastos de los miembros del CNEL; a la designación de representantes en los organismos públicos de carácter nacional; y a la aprobación del estado de cuentas: en todos estos casos, los reglamentos se someten a aprobación, mediante decreto del Presidente de la República, a propuesta del Presidente del Gobierno y previa deliberación en Consejo de Ministros.

Desde esta perspectiva, pues, se ha garantizado una mayor autonomía del CNEL. Pero, obsérvese, ello no comporta en absoluto que tales actos reglamentarios se sitúen -en cuanto a las posiciones dentro del sistema de fuentes - al nivel de los reglamentos de las Cámaras o del Tribunal Constitucional; es decir, no cabe siquiera plantear que los reglamentos del CNEL sean actos normativos de rango primario. Estamos, pues, frente a actos de normación secundaria que gozan de una esfera de competencia garantizada por la ley que los ha previsto.

6. Si de un lado - como hasta aquí se ha tratado de demostrarla ley núm. 936 no parece haber reforzado las funciones tradicionales del CNEL, aun cuando ha eliminado los límites que anteriormente acompañaban a su ejercicio, de otro, ha previsto nuevas funciones que podrían surtir efecto en el intento de revitalizar la presencia de la institución dentro del sistema. Nos referimos, en concreto, a la aprobación periódica de «informes sobre la situación general, sectorial y local del mercado de trabajo, y sobre los sistemas normativos y retributivos derivados de los convenios colectivos" (art. 10, c), asi como a las "evaluaciones de la coyuntura económica en sesiones semestrales" y al correspondiente poder de remitir, a tal efecto, «directivas a las instituciones encargadas de establecer las bases del sistema" (art. 10, c). En previsión de tales funciones el Consejo cuenta con el apoyo de una Comisión para la información (art. 16) con importantes poderes de investigación en el sector económico-social. Además, se halla adscrito al CNEL el Archivo Nacional de Contratos y Convenios Colectivos de Trabajo en el que, por las partes firmantes, debe depositarse una copia autentificada tanto de los nuevos convenios como de las revisiones, en el plazo de treinta días desde su firma (art. 17, pfos. 1-3). Por último, la ley prevé la existencia de un «banco de datos sobre el mercado de trabajo, costes y condiciones de trabajo en cuyo establecimiento y actualización colaborarán los entes públicos que tengan competencias en tales materias" (art. 17, pfo. 4).

Mediante el conjunto de disposiciones que hemos citado, se le ha asignado al CNEL un significativo papel de análisis de la dinámica económico-social del país, apoyándolo, asi, en otros institutos (por ejemplo, CENSIS, ISTAT) que desarrollan actividades afines. Pero, principalmente con la creación del Archivo de convenios colectivos nacionales -única sede institucional de depósito de tales actos- el Parlamento ha pretendido llevar a cabo uuna operación dirigida a lograr que las organizaciones so- 
ciales, a través del CNEL, realicen una evaluación periódica de las incidencias del sistema retributivo y del comportamiento del mercado de trabajo, especialmente desde la perspectiva normativa de la contratación» (cfr., Actas de la Cámara de Diputados - IX Legislatura-Proyectos de Ley y Dictámenes, núm. 3566).

Ciertamente, por esta via el carácter «auxiliar» del CNEL parece sufrir una profunda mutación: ya no son los «meros» intereses los que constituyen la base de información necesaria a la actividad consultiva del órgano sino las evaluaciones operadas sobre la base de una permanente observación de las mutaciones del sistema de relaciones industriales. Aunque con estos planteamientos se diluye la ratio de las disposiciones antes mencionadas y en cuya virtud han quedado acentuadas las características de la institución como órgano de representación de intereses. Ante todo, si el CNEL debe acabar desarrollando una función de "super asesoría» resulta difícil comprender por qué ha quedado reducida la representación de los «expertos» en su seno. En definitiva, si la Ley de Reforma ha puesto fin a algunas ambigüedades presentes en el ordenamiento precedente, ha contribuido, también, a permitir el planteamiento de otras nuevas. 